\title{
Programmed cell death 4 inhibits leptin-induced breast cancer cell invasion
}

\author{
VIANEY GONZÁLEZ-VILLASANA ${ }^{1,2}$, RENÉ NIEVES-ALICEA ${ }^{3}$, \\ VANITY McMURTRY ${ }^{2}$, YOLANDA GUTIÉRREZ-PUENTE ${ }^{1}$ and ANA M. TARI ${ }^{2,4}$
}

\begin{abstract}
${ }^{1}$ Departamento de Bioquímica, Facultad de Ciencias Biológicas, Universidad Autónoma de Nuevo León, San Nicolás de los Garza, N.L., México; ${ }^{2}$ Department of Experimental Therapeutics, University of Texas M.D. Anderson Cancer Center, Houston, TX; ${ }^{3}$ Department of Nanomedicine and Biomedical Engineering, University of Texas Health Science Center, Houston, TX; ${ }^{4}$ Division of Hematology-Oncology, University of Florida, Gainesville, FL, USA
\end{abstract}

Received September 12, 2011; Accepted October 24, 2011

DOI: $10.3892 /$ or.2011.1600

\begin{abstract}
Obesity is a significant risk factor for post-menopausal women to develop and die from breast cancer. Leptin, an adipokine is produced in high levels in obese individuals, and its receptor is overexpressed in breast tumors and lymph node metastases. Previously, we demonstrated that leptin stimulates breast cancer cell invasion, which is correlated with breast cancer metastasis. Programmed cell death 4 (PDCD4) has been shown to block cancer cell invasion. However, whether PDCD4 blocks leptin-induced breast cancer cell invasion is not known. Here, we report the novel findings that leptin failed to induce invasion in MCF-7 breast cancer cells overexpressing PDCD4 (MCF-7/PDCD4). Tissue inhibitor of metalloproteinase-2 (TIMP-2) was essential to the anti-invasive effect of PDCD4, as leptin stimulated the invasion of MCF-7/ PDCD4 cells pretreated with TIMP-2 siRNA. Furthermore, TIMP-2 knockdown allowed leptin to augment phosphorylation of extracellular signal-regulated kinases 1,2 and signal transducer and activator of transcription 3, but not that of Jun $\mathrm{N}$-terminal kinases. These data indicate that PDCD4 utilizes TIMP-2 to exert its anti-invasive effect by suppressing leptininduced activation of extracellular signal-regulated kinases 1,2 and signal transducer and activator of transcription 3. Novel therapeutic strategies aiming at enhancing PDCD4 expression in breast tumors may be able to stop obesity-related breast tumor progression and prolong the life of patients.
\end{abstract}

Correspondence to: Dr Ana M. Tari, Division of Hematology and Oncology, University of Florida, 2033 Mowry Road, P.O. Box 103633, Gainesville, FL 32611-3633, USA

E-mail: ana.tari@medicine.ufl.edu

Abbreviations: ERK1,2, extracellular signal-regulated kinases 1,2; JNK, Jun N-terminal kinases; PDCD4, programmed cell death 4; STAT3, signal transducers and activators of transcription 3; TIMP-2, tissue inhibitor of metalloproteinase-2

Key words: breast cancer invasion, leptin, programmed cell death 4, tissue inhibitor of metalloproteinase-2

\section{Introduction}

Breast cancer is the most frequently diagnosed cancer in women. In 2010, about 207,090 new cases of invasive breast cancer were expected to be diagnosed among women, and about 39,840 women were expected to die from breast cancer. One of the major risk factors for postmenopausal women to develop breast cancer is obesity. Tumors from breast cancer patients with high body mass index are typically of the hormoneresponsive type (1-3). Leptin, a $16-\mathrm{kDa}$ hormone that was discovered as a regulator of body weight and energy balance acting in the hypothalamus (4), is an important hormonal link between obesity and breast cancer. As body weight and fat mass increase, the level of circulating leptin increases $(5,6)$.

High expression of leptin and the long/signaling form of leptin receptor have been found in breast tumors (7-11). Leptin-deficient mice have decreased incidence of oncogeneinduced mammary tumors (12). An inhibitor targeted to the leptin receptor suppresses breast tumor formation in vivo (13). High levels of leptin in breast tumors have been correlated with poorer patient prognosis and increased incidence of metastasis $(7,10,11)$. Breast cancer metastasis is directly associated with breast cancer cell invasion. Recently, we showed that leptin stimulates invasion of MCF-7 breast cancer cells by activating Jun N-terminal kinases (JNK), which increase matrix metalloproteinase-2 activity (14).

Leptin has also been associated with the development of anti-estrogen resistance. Leptin is a potent modulator of the estrogen receptor signaling pathway (15-17). Leptin stimulates the production of estrogen by increasing aromatase expression. Leptin activates estrogen receptor in a ligand-independent manner. Further, leptin stabilizes the estrogen receptor by interfering with the proteasome-mediated degradation of this receptor. Therefore, high expression of leptin may be associated with poorer prognosis in breast cancer patients because it stimulates invasion and anti-estrogen resistance in breast cancer cells. Novel therapeutic strategies aiming at disrupting leptin signaling in breast tumors may be able to impede obesityrelated breast tumor progression and prolong patients' lives.

Programmed cell death 4 (PDCD4), originally identified as an inhibitor of murine cellular transformation, is a novel 
tumor suppressor. Expression of PDCD4 is decreased or lost in several tumors, including invasive ductal breast tumors (18). We showed that by increasing tissue inhibitor of metalloproteinase-2 (TIMP-2) expression, PDCD4 overexpression suppresses breast cancer cell invasion mediated by prostaglandin $\mathrm{E}_{2}$ or interleukin-8 (19). However, it is not known whether PDCD4 could suppress leptin-induced breast cancer cell invasion.

In the present study, we report the novel finding that PDCD4 overexpression blocks leptin-induced invasion of MCF-7 breast cancer cells. We also report that PDCD4 overexpression utilizes TIMP-2 to block leptin-induced invasion by decreasing activities of extracellular signal-regulated kinases 1,2 (ERK1,2), and signal transducer and activator of transcription 3 (STAT3).

\section{Materials and methods}

Cell lines and culture conditions. Parental MCF-7 (MCF-7/ WT) human breast cancer cells were stably transfected with empty pcDNA3.1 plasmid vector (MCF-7/Vector) or with pcDNA3.1 plasmid encoding the human PDCD4 gene (MCF-7/PDCD4) (19). MCF-7/Vector and MCF-7/PDCD4 cells were maintained in Dulbecco's modified Eagle's medium (DMEM/F12) (Invitrogen Corp.) supplemented with 5\% fetal bovine serum (FBS) and $500 \mu \mathrm{g} / \mathrm{ml}$ of geneticin.

Matrigel invasion. The invasiveness of MCF-7 and MCF-7/ PDCD4 cells treated with leptin was determined as previously described $(14,19)$ by counting the number of cells that invaded through transwell inserts coated with the Matrigel artificial basement membrane. Briefly, MCF-7 and MCF-7/PDCD4 cells were collected and washed with serum-free media. Cells $\left(4 \times 10^{5}\right)$ were resuspended in $1 \mathrm{ml}$ of serum-free DMEM/F-12 medium and added into 6 -well plate transwell inserts $(8 \mu \mathrm{m}$ pore-size; Fisher Scientific, Middleton, VA, USA) coated with a Matrigel basement membrane $(0.7 \mathrm{mg} / \mathrm{ml}$; BD Biosciences, Bedford, MA, USA). The lower chambers were filled with $2 \mathrm{ml}$ of DMEM/F-12 medium supplemented with $10 \%$ FBS. Cells in the transwell inserts were then treated with 0,10 and $100 \mathrm{ng} / \mathrm{ml}$ of leptin in serum-free media. Seventy-two hours later, non-invading cells on the upper surface of the filter were removed with cotton swabs. Cells that invaded through the Matrigel onto the lower side of the filter were fixed, stained with the Hema-3 Stain System (Fisher Scientific), and photographed. For each filter, the number of invaded cells was counted in nine fields, and expressed as the mean number of cells of triplicate measurements. Two-sample t-tests were used to compare the number of invaded cells.

siRNA transfection. MCF-7/PDCD4 cells were plated at a density of $2 \times 10^{5}$ cells/well in 6 -well plates. The next day, cells were transfected with $200 \mathrm{nM}$ human TIMP-2 (Thermo Scientific) or non-silencing control siRNA (Qiagen) using HiPerFect ${ }^{\circledR}$ transfection reagent (Qiagen, Valencia, CA, USA). Forty-eight hours later, cells were harvested, plated at a density of $1 \times 10^{5}$ cells/well and treated with $100 \mathrm{ng} / \mathrm{ml}$ leptin in DMEM/F12 medium containing 5\% FBS for an additional $72 \mathrm{~h}$. Cells were collected for RT-PCR and Western blot analysis. Similarly, after cells were transfected with TIMP-2 or non-silencing control siRNA, cells were collected and invasion assays were performed as described above.

RNA isolation and reverse transcription-polymerase chain reaction $(R T-P C R)$. To confirm that the level of TIMP-2 mRNA was reduced in cells transfected with TIMP-2 siRNA, total RNA was extracted using the RNeasy Mini kit (Qiagen). RNA $(1 \mu \mathrm{g})$ was used in the SuperScript III one-step RT-PCR System (Invitrogen Corp.). TIMP-2 and GAPDH primer sequences have been previously described (19). GAPDH was used as loading control. TIMP-2: forward, 5'-GGT CTC GCT GGA CGT TGG AG-3' and reverse, 5'-GGA GCC GTC ACT TCT CTT G-3'. GAPDH: forward, 5'-GCC AAG GTC ATC CAT GAC AAC-3' and reverse, 5'-GTC CAC CAC CCT GTT GCT GTA-3'. The PCR conditions for all reactions were performed as described (19): $55^{\circ} \mathrm{C}$ for $30 \mathrm{~min}, 94^{\circ} \mathrm{C}$ for $2 \mathrm{~min}, 30$ cycles of $94^{\circ} \mathrm{C}$ for $15 \mathrm{sec}, 57^{\circ} \mathrm{C}$ for $30 \mathrm{sec}, 68^{\circ} \mathrm{C}$ for $1 \mathrm{~min}$, and $68^{\circ} \mathrm{C}$ for $5 \mathrm{~min}$.

Western blotting. Western blotting was performed as described (14). Cells were harvested with cold PBS, and lysed with ice-cold lysis buffer and incubated on ice for $30 \mathrm{~min}$. Lysates were centrifuged, supernatants were collected, and protein concentration was determined using the DC Protein Assay (Bio-Rad Laboratories, Hercules, CA). Samples were electrophoresed on $10 \%$ polyacrylamide gels (BioRad Laboratories), and then transferred to nitrocellulose membranes (Bio-Rad Laboratories). Membranes were blocked in Tris-buffered saline (20 mM Tris $\mathrm{pH} 7.6,150 \mathrm{mM} \mathrm{NaCl})$ with $0.1 \%$ Tween-20 containing 5\% non-fat dry milk at room temperature for $30 \mathrm{~min}$. After washing, primary antibodies, such as phosphorylated ERK1,2 $\left(\mathrm{T}^{202} / \mathrm{Y}^{204}\right)$, total ERK1,2, phosphorylated STAT3 ( $\left.\mathrm{Y}^{705}\right)$, and total STAT3, phosphorylated Jun N-terminal kinases (JNK) $\left(\mathrm{T}^{183} / \mathrm{Y}^{185}\right)$, and total JNK, were added to membranes at 1:1,000 dilution. After overnight incubation at $4^{\circ} \mathrm{C}$, membranes were washed and incubated with anti-rabbit secondary antibody conjugated with horseradish peroxidase. Proteins bands were detected via enhanced chemiluminescence (GE Healthcare, Piscataway, NJ). Images were scanned by an AlphaImager densitometer (Alpha Innotech Corp., San Leandro, CA). $\beta$-actin or Grb-2 were used as loading controls. Membranes were incubated with anti- $\beta$-actin antibody (1:10,000 dilution) or anti-Grb-2 antibody (1:5,000 dilution) for $30 \mathrm{~min}$ at room temperature, washed, and incubated with anti-mouse secondary antibody (1:10,000 dilution) for another $30 \mathrm{~min}$ at room temperature.

\section{Results}

PDCD4 inhibits leptin-induced breast cancer cell invasion. We used Western blot analysis to confirm that MCF-7/PDCD4 cells express higher levels of PDCD4 protein than control MCF-7 cells. MCF-7/PDCD4 cells expresssed 1.5-fold higher PDCD4 levels than control cells (Fig. 1A). We next performed Matrigel invasion assays after treating control MCF-7 cells and MCF-7/PDCD4 cells with 0, 10 and $100 \mathrm{ng} / \mathrm{ml}$ of leptin. In the absence of leptin, the number of invaded MCF-7 cells averaged 55 (Fig. 1B). In the presence of 10 and $100 \mathrm{ng} / \mathrm{ml}$ leptin, the number of invaded cells averaged 100 and 140 , respectively (Fig. 1B). This confirmed our earlier report that 
A
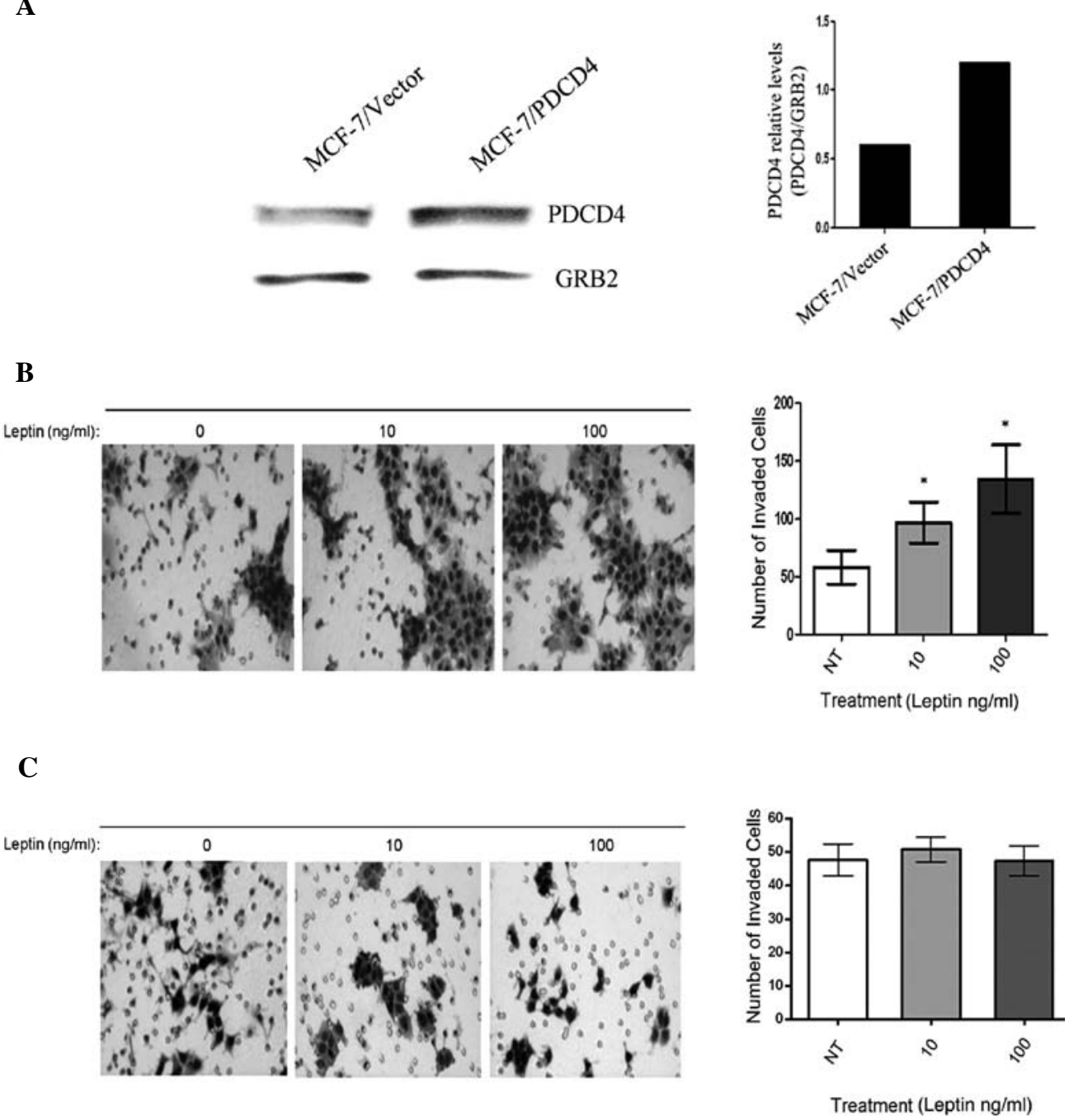

Figure 1. PDCD4 inhibits leptin-induced breast cancer cell invasion. (A) Western blot analysis was used to confirm higher PDCD4 expression in MCF-7/ PDCD4 cells than in MCF-7/Vector cells. Matrigel invasion assay was performed to determine the effects of leptin on the invasiveness of (B) MCF-7/WT cells and (C) MCF-7/PDCD4 cells. The number of invaded cells was significantly higher in the leptin-treated vs. the untreated cells, ${ }^{*} \mathrm{p}<0.05$.

leptin stimulates the invasion of MCF-7 cells (14). On the other hand, leptin did not stimulate the invasion of MCF-7/PDCD4 cells; in the presence of 0,10 and $100 \mathrm{ng} / \mathrm{ml}$ leptin, the average numbers of invaded MCF-7/PDCD4 cells were 48, 51, and 47, respectively (Fig. 1C). These data indicate that high level of PDCD4 blocks leptin-induced breast cancer cell invasion.

TIMP-2 is essential for PDCD4 to block leptin-induced breast cancer cell invasion. We were interested in determining whether TIMP-2 is essential to the anti-invasive effect of PDCD4. This is because previously we showed that PDCD4 overexpression blocks prostaglandin $\mathrm{E}_{2^{-}}$or interleukin8 -induced invasion of breast cancer cells by increasing TIMP-2 expression (19). We used RT-PCR to determine the TIMP-2 mRNA levels in MCF-7/WT, MCF-7/Vector and MCF-7/PDCD4 cells. TIMP-2 mRNA levels were $2.1-$ and 1.5-fold higher in MCF-7/PDCD4 cells than in MCF-7/ WT and MCF-7/Vector cells, respectively (Fig. 2A). To determine whether TIMP-2 is essential for PDCD4 to block leptin-induced breast cancer cell invasion, we treated MCF-7/ PDCD4 cells with TIMP-2 siRNA or with control siRNA (Fig. 2B), and then performed the Matrigel invasion assay.
When $100 \mathrm{ng} / \mathrm{ml}$ of leptin were used, the average numbers of untreated and control siRNA-treated MCF-7/PDCD4 cells that invaded through the Matrigel were 60 and 62, respectively (Fig. 2C). But under identical conditions, the average number of TIMP-2-treated MCF-7/PDCD4 cells that invaded through the Matrigel was 220 (Fig. 2C). These data demonstrate that when TIMP-2 expression is down-regulated, the invasiveness of leptin-induced MCF-7/PDCD4 cells increased significantly, indicating that TIMP-2 is essential for PDCD4 to block leptininduced breast cancer cell invasion.

TIMP-2 knockdown increases leptin-induced phosphorylated ERK1,2 and phosphorylated STAT3 levels in MCF-7/PDCD4 cells. Leptin has been shown to activate ERK1,2, STAT3, and JNK in breast cancer (13-16,20-24). We proposed that TIMP-2 suppresses leptin-induced breast cancer cell invasion by reducing the activities of ERK1,2, STAT3, and/or JNK. Therefore, we expected TIMP-2 knockdown to increase leptininduced ERK1,2, STAT3, and/or JNK phosphorylation. We pretreated MCF-7/PDCD4 cells with TIMP-2 siRNA or with control siRNA, before treating them with leptin. Western blot analysis was utilized to investigate the phosphorylated levels 
A
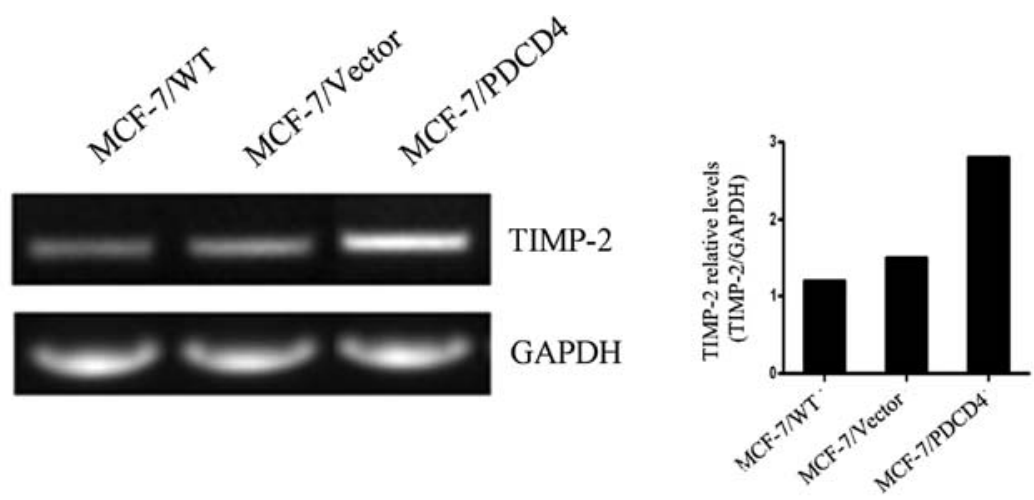

B
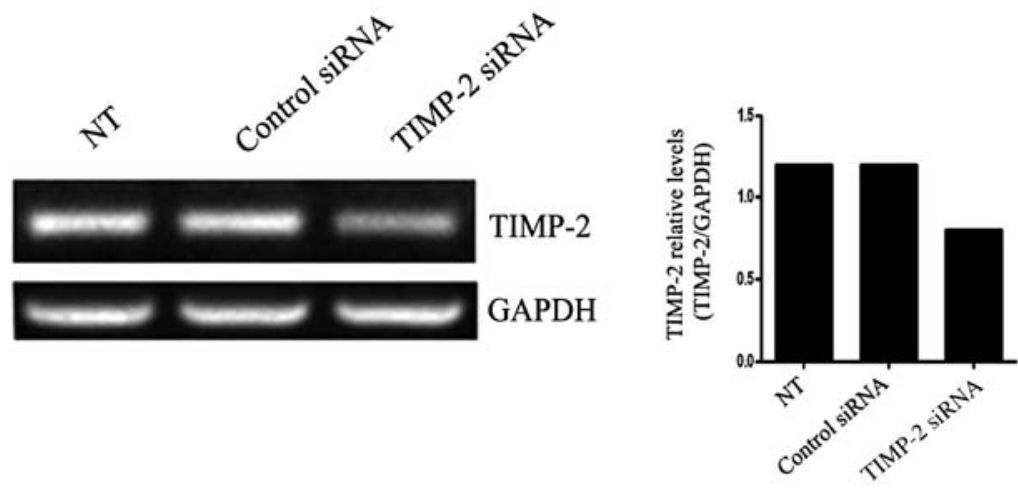

\section{C}
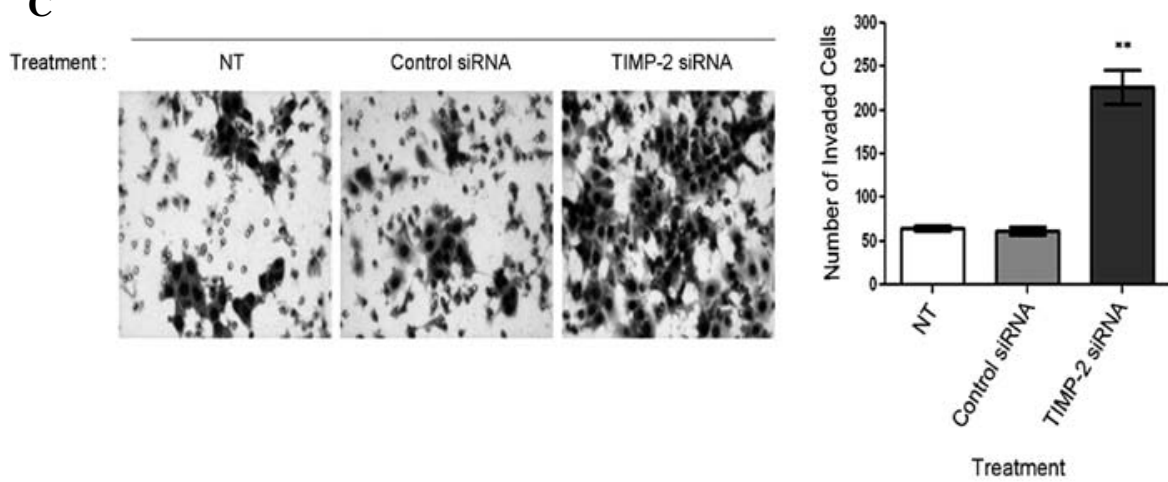

Figure 2. TIMP-2 is essential for PDCD4 to suppress leptin-induced breast cancer cell invasion. (A) RT-PCR was performed to determine TIMP-2 mRNA levels in breast cancer cells. (B) RT-PCR was performed to confirm that TIMP-2 siRNA reduced TIMP-2 mRNA expression. (C) TIMP-2 knockdown increased leptin-induced MCF-7/PDCD4 breast cancer cell invasion. " $\mathrm{p}<0.05$, number of invaded cells transfected with TIMP-2 siRNA compared to cells transfected with control siRNA.

of ERK1,2, STAT3, and JNK. In the presence of leptin, MCF-7/PDCD4 cells treated with TIMP-2 siRNA expressed 2-fold higher levels of phosphorylated ERK1,2 than control siRNA-treated cells (Fig. 3A), and 2.5-fold higher levels of phosphorylated STAT3 than control siRNA-treated cells (Fig. 3B). However, under identical conditions, there was no difference in the levels of phosphorylated JNK between TIMP-2 siRNA- and control siRNA-treated MCF-7/PDCD4 cells (Fig. 3C). These results show that TIMP-2 down-regulation allows leptin to stimulate ERK1,2 and STAT3 activities in MCF-7/PDCD4 cells.

Interestingly, TIMP-2 knockdown led to an increase in phosphorylated ERK1,2 levels but a decrease in total ERK1,2 levels. Yet, TIMP-2 knockdown stimulated phosphorylated STAT3 levels without affecting total STAT3 levels. We speculate that a feedback mechanism may exist regulating the ratio of phosphorylated ERK1,2 to total ERK1,2 levels.

\section{Discussion}

Obesity is a mortality risk factor for women diagnosed with breast cancer; women with a body mass index of at least 40 have a 2.1-fold elevated risk of death from breast cáncer (25). Leptin is a vital link between obesity and breast cancer, as high levels of leptin in breast tumors have been associated with poorer patient prognosis and increased incidence of metastasis $(7,10,11)$. Novel therapeutic strategies are needed to impede leptin-mediated breast tumor progression.

Here, we show for the first time that PDCD4 inhibits leptininduced breast cancer cell invasion. Similarly to our previous report (19), we observed that TIMP-2 is critical to the antiinvasive effects of PDCD4. Leptin stimulated the invasion of MCF-7/PDCD4 cells when TIMP-2 expression was knocked down. Interestingly, PDCD4 expression is only slightly decreased in ductal carcinoma in situ samples in comparison 
A

\section{LEPTIN $[100 \mathrm{ng} / \mathrm{ml}]$}
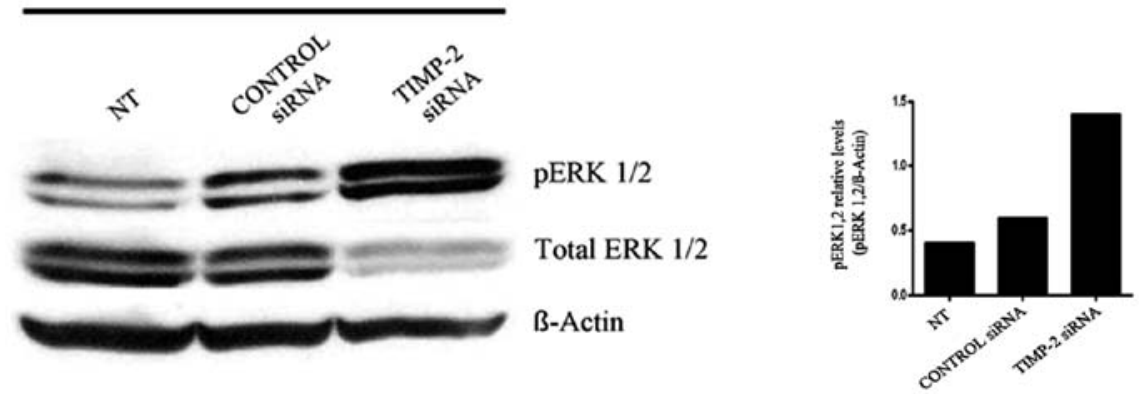

B
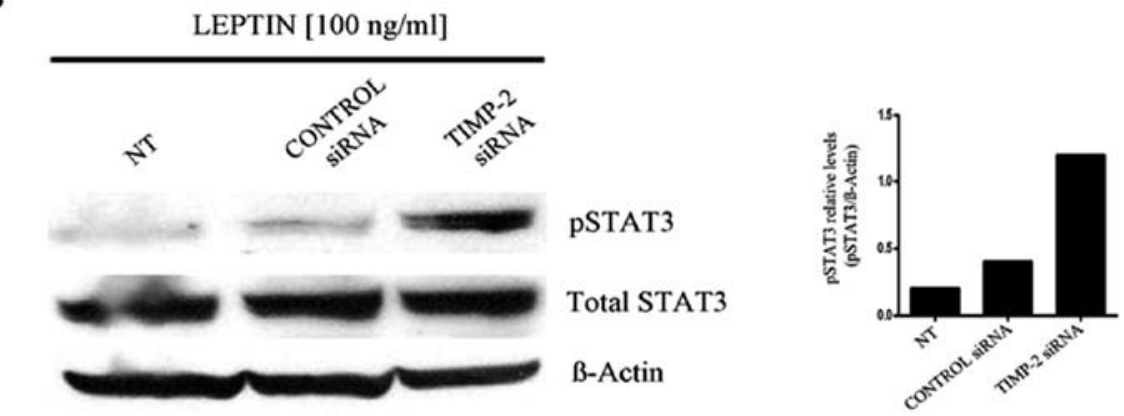

C
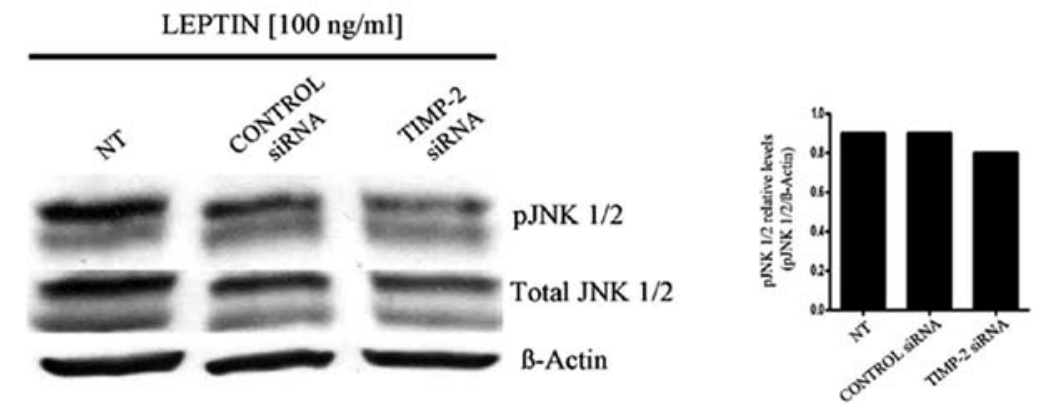

Figure 3. TIMP-2 knockdown increases leptin-induced phosphorylated ERK1,2 and STAT3 levels. MCF-7/PDCD4 cells were transfected with TIMP-2 or control siRNA for $48 \mathrm{~h}$, before being treated with leptin. Western blot analysis was used to determine (A) phosphorylated ERK1,2 and total ERK1,2 levels, (B) phosphorylated STAT3 and total STAT3 levels, and (C) phosphorylated JNK and total JNK levels.

to normal breast epithelial cells, but is markedly decreased in invasive ductal carcinoma samples (26). Thus, PDCD4 may act as a breast tumor suppressor by blocking breast cancer cell invasion.

Here, we have also studied the mechanisms by which PDCD4 utilizes TIMP-2 to exert its anti-invasive effects. Leptin is known to stimulate ERK1,2, STAT3, and JNK phosphorylation in breast cancer cells (13-16,20-24). We found that TIMP-2 knockdown allows leptin to augment ERK1,2, and STAT3 phosphorylation in MCF-7/PDCD4 cells, indicating that PDCD4 utilizes TIMP-2 to counteract leptin-mediated activation of ERK1,2 and STAT3 to block invasion. Indeed, ERK1,2 and STAT3 are essential to leptin-stimulated invasion, as pharmacological inhibitors of JAK2/STAT3 and ERK1,2 blocked leptin-mediated invasion of hepatocellular and endometrial carcinoma cells $(22,27)$. However, TIMP-2 knockdown did not change leptin-mediated JNK phosphorylation levels, indicating that TIMP-2 is not utilized by PDCD4 in the regulation of JNK activity. PDCD4 has been shown to inhibit the transcription of mitogen-activated protein kinase kinase kinase kinase 1 (MAP4K1) (28), a kinase upstream of JNK, thereby inhibiting c-Jun activation and AP-1-dependent transcription (28). Alternatively, PDCD4 could inhibit AP-1dependent transcription by interfering with the recruitment of the coactivator p300 by c-Jun, and suppresses the phosphorylation of c-Jun by JNK (29).

In conclusion, our results demonstrate that overexpression of PDCD4 led to increased transcription of TIMP-2 which can overcome leptin-induced breast cancer cell invasion by blocking ERK1,2 and STAT3 activation. Novel therapeutic strategies aiming at enhancing PDCD4 expression in breast tumors may be able to impede obesity-related breast tumor progression and prolong patients' lives.

\section{Acknowledgements}

This study was supported by the Susan G. Komen Breast Cancer Foundation (A.M.T.). 


\section{References}

1. Verreault R, Brisson J, Deschenes L and Naud F: Body weight and prognostic indicators in breast cancer. Modifying effect of estrogen receptors. Am J Epidemiol 129: 260-268, 1989.

2. Giuffrida D, Lupo L, La Porta GA, et al: Relation between steroid receptor status and body weight in breast cancer patients. Eur J Cancer 28: 112-115, 1992.

3. Huang WY, Newman B, Millikan RC, Schell MJ, Hulka BS and Moorman PG: Hormone-related factors and risk of breast cancer in relation to estrogen receptor and progesterone receptor status. Am J Epidemiol 151: 703-714, 2000.

4. Zhang Y, Proenca R, Maffei M, Barone M, Leopold L and Friedman JM: Positional cloning of the mouse obese gene and its human homologue. Nature 372: 425-432, 1994.

5. Sinha MK, Opentanova I, Ohannesian JP, et al: Evidence of free and bound leptin in human circulation. Studies in lean and obese subjects and during short-term fasting. J Clin Invest 98 : 1277-1282, 1996.

6. McGregor GP, Desaga JF, Ehlenz K, et al: Radiommunological measurement of leptin in plasma of obese and diabetic human subjects. Endocrinology 137: 1501-1504, 1996.

7. Ishikawa M, Kitayama J and Nagawa H: Enhanced expression of leptin and leptin receptor (OB-R) in human breast cancer. Clin Cancer Res 10: 4325-4331, 2004.

8. Miyoshi Y, Funahashi T, Tanaka S, et al: High expression of leptin receptor mRNA in breast cancer tissue predicts poor prognosis for patients with high, but not low, serum leptin levels. Int J Cancer 118: 1414-1419, 2006.

9. Caldefie-Chezet F, Damez M, de Latour M, et al: Leptin: a proliferative factor for breast cancer? Study on human ductal carcinoma. Biochem Biophys Res Commun 334: 737-741, 2005.

10. Garofalo C, Koda M, Cascio S, et al: Increased expression of leptin and the leptin receptor as a marker of breast cancer progression: possible role of obesity-related stimuli. Clin Cancer Res 12: 1447-1453, 2006.

11. Revillion F, Charlier M, Lhotellier V, et al: Messenger RNA expression of leptin and leptin receptors and their prognostic value in 322 human primary breast cancers. Clin Cancer Res 12: 2088-2094, 2006.

12. Cleary MP, Juneja SC, Phillips FC, Hu X, Grande JP and Maihle NJ: Leptin receptor-deficient MMTV-TGF-alpha/ Lepr(db)Lepr(db) female mice do not develop oncogene-induced mammary tumors. Exp Biol Med (Maywood) 229: 182-193, 2004.

13. Gonzalez RR, Cherfils S, Escobar M, et al: Leptin signaling promotes the growth of mammary tumors and increases the expression of vascular endothelial growth factor (VEGF) and its receptor type two (VEGF-R2). J Biol Chem 281: 26320-26328, 2006.

14. McMurtry V, Simeone AM, Nieves-Alicea R and Tari AM: Leptin utilizes Jun N-terminal kinases to stimulate the invasion of MCF-7 breast cancer cells. Clin Exp Metastasis 26: 197-204, 2009.
15. Catalano S, Marsico S, Giordano C, et al: Leptin enhances, via AP-1, expression of aromatase in the MCF-7 cell line. J Biol Chem 278: 28668-28676, 2003.

16. Catalano S, Mauro L, Marsico S, et al: Leptin induces, via ERK1/ ERK2 signal, functional activation of estrogen receptor alpha in MCF-7 cells. J Biol Chem 279: 19908-19915, 2004.

17. Garofalo C, Sisci D and Surmacz E: Leptin interferes with the effects of the antiestrogen ICI 182,780 in MCF-7 breast cancer cells. Clin Cancer Res 10: 6466-6475, 2004.

18. Jansen AP, Camalier CE, Stark C and Colburn NH: Characterization of programmed cell death 4 in multiple human cancers reveals a novel enhancer of drug sensitivity. Mol Cancer Ther 3: 103-110, 2004.

19. Nieves-Alicea R, Colburn NH, Simeone AM and Tari AM: Programmed cell death 4 inhibits breast cancer cell invasion by increasing tissue inhibitor of metalloproteinases- 2 expression. Breast Cancer Res Treat 114: 203-209, 2009.

20. Yin N, Wang D, Zhang H, et al: Molecular mechanisms involved in the growth stimulation of breast cancer cells by leptin. Cancer Res 64: 5870-5875, 2004

21. Chen C, Chang YC, Liu CL, Chang KJ and Guo IC: Leptininduced growth of human ZR-75-1 breast cancer cells is associated with up-regulation of cyclin D1 and c-Myc and downregulation of tumor suppressor p53 and p21WAF1/CIP1. Breast Cancer Res Treat 98: 121-132, 2006.

22. Saxena NK, Sharma D, Ding X, et al: Concomitant activation of the JAK/STAT, PI3K/AKT, and ERK signaling is involved in leptin-mediated promotion of invasion and migration of hepatocellular carcinoma cells. Cancer Res 67: 2497-2507, 2007.

23. Ray A, Nkhata KJ and Cleary MP: Effects of leptin on human breast cancer cell lines in relationship to estrogen receptor and HER2 status. Int J Oncol 30: 1499-1509, 2007.

24. Jiang H, Yu J, Guo H, Song $H$ and Chen S: Upregulation of survivin by leptin/STAT3 signaling in MCF-7 cells. Biochem Biophys Res Commun 368: 1-5, 2008.

25. Calle EE, Rodriguez C, Walker-Thurmond $\mathrm{K}$ and Thun MJ: Overweight, obesity, and mortality from cancer in a prospectively studied cohort of U.S. adults. N Engl J Med 348: 1625-1638, 2003.

26. Wen YH, Shi X, Chiriboga L, Matsahashi S, Yee H and Afonja O: Alterations in the expression of PDCD4 in ductal carcinoma of the breast. Oncol Rep 18: 1387-1393, 2007.

27. Sharma D, Saxena NK, Vertino PM and Anania FA: Leptin promotes the proliferative response and invasiveness in human endometrial cancer cells by activating multiple signal-transduction pathways. Endocr Relat Cancer 13: 629-640, 2006.

28. Yang HS, Matthews CP, Clair T, et al: Tumorigenesis suppressor Pdcd4 down-regulates mitogen-activated protein kinase kinase kinase kinase 1 expression to suppress colon carcinoma cell invasion. Mol Cell Biol 26: 1297-1306, 2006.

29. Bitomsky N, Bohm M and Klempnauer KH: Transformation suppressor protein Pdcd4 interferes with JNK-mediated phosphorylation of c-Jun and recruitment of the coactivator p300 by c-Jun. Oncogene 23: 7484-7493, 2004. 